\title{
ADAPTIVE CONTROL OF CHEMICAL REACTOR USING NEURAI NETWORKS
}

ffg areed, HANY ABDELFATTAH

\author{
Abstract \\ Control strategies based on nonlinear \\ process models can provide the \\ potential for significant improvement \\ over 1 inear c ontroliers $f$ or $n$ onlinear \\ processes. An adaptive neural \\ network is applied to a rauitivariable \\ chemical reactor. The first stage of \\ tlie project, simulation study, has \\ been investigated and is presented in \\ tliis paper. A radial basis function \\ network is developed to model the \\ real process, and its weights are on $\neg$ \\ line updated using a self organizing- \\ map (kohonen algorithm). Design of \\ a Proportional-Integral-Derivative \\ (PID) linear controller for a chemical \\ process is presented. Comparison \\ between PID controller and a neural \\ network-based kohonen algorithni \\ controller are illustrated by the \\ simulation results. Results howed \\ tlie proposed technique controller that \\ .induce a linear response, in input- \\ output sense and that the nonlinear \\ controller can be easily tuned.
}

